\title{
Analisis Tataniaga Kambing Di Pasar Hewan Wlingi Kabupaten Blitar
}

\author{
M Zainul Ifanda \\ Mahasiswa Program Studi Ilmu Ternak Fakultas Peternakan \\ Universitas Islam Balitar \\ Jl. Majapahit No. 04 Kota Blitar
}

\begin{abstract}
ABSTRACK
At the process trade of goat in Blitar, esspecially in animal market "Terpadu" Wlingi that is "pasaran" (in Indonesia) Tuesday, Thrusday, and Saturday and also there is some channel of trade, and kinds of cost that issued efery channel.This research to know groove of trading goat and farmer's share in Blitar especiaally animal market "terpadu" Wlingi.

Method of research that used is survey, used sunaple more that 10 traders that experienced of trader minimal 5 years. Result of research to show that there is marketing that "blantik", breeder, customer, and grocier big. Margin of marketing higher is Rp 750.000 efery goat. Farmer's share that received breeder higher that first channel (breeder-costumer) is $100 \%$. The channel of marketing that first channel is so eficient. Cost and margin a lowest at first channel. Farmer's share is lowest at third channel. Channel of marketing at first channel more eficientli because it has done Farmer's share more higher is $100 \%$.
\end{abstract}

Keywords: Goat, Commerce, Wlingi Blitar.

\section{PENDAHULUAN}

Peternakan merupakan salah satu subsektor dari kegiatan Pertanian yang dapat di jadikan sebagai komoditas unggulan bagi suatu wilayah. Peternakan dapat dibedakan menjadi 3 komoditi, yaitu ternak besar, ternak kecil, unggas. Yang tergolong dalam ternak besar yaitu : sapi ( potong dan perah ), kerbau, dan kuda. Komoditi ternak kecil terdiri dari kambing, domba, dan babi. Sedangkan yang tergolong dalam ternak unggas adalah ayam, itik, dan burung (BPS, 2007). Kabupaten Blitar mempunyai komoditas unggulan dari sektor peternakan yaitu salah satunya kambing. Kabupaten Blitar merupakan sentra perdagangan kambing. permintaan akan kambing di Kabupaten Blitar ini semakin hari semakin meningkat, hal ini dikarenakan kambing tersebut mempunyai beberapa manfaat yaitu dapat menghasilkan daging, kulit, dan susu segar. Peningkatan permintaan terhadap kambing menyebabkan fluktuasi harga dan pasokan kambing tersebut.

Dalam proses distribusi dan pemasaran kambing tersebut dari produsen ke konsumen tidak lepas dari peran beberapa lembaga pemasaran yang dalam proses pemasaran sering disebut lembaga perantara. Para produsen kambing kadang tidak mengetahui harga pasar. Hal ini di sebabkan oleh adanya jarak antara produsen dengan konsumen akhir yang terlalu jauh. Sehingga peran dari lembaga perantara tersebut sangat penting dalalm proses distribusi dan pemasaran. Dengan semakin banyaknya peran lembaga perantara maka rantai pemasaran dari produsen ke konsumen akhir semakin panjang dan mengakibatkan marjin pemasaran semakin tinggi. Penelitian ini bertujuan untuk mengetahui berbagai biaya pemasaran kambing yang terjadi di Kabupaten Blitar khususnya di Pasar Hewan Wlingi dan manakah saluran pemasaran yang menguntungkan bagi lembaga pemasaran.

\section{METODE PENELITIAN}

Lokasi penelitian dilakukan di Pasar Hewan Wlingi Kabupaten Blitar. Penelitian di lakukan dengan survey langsung mendatangi ke lokasi pasar, penelitian ini di lakukan tiga 
kali dalam satu minggu pada hari selasa, kamis, dan sabtu, di mulai pada bulan januari sampai mei 2015. Data yang dikumpulkan berupa data primer dan data sekunder. Data prirner diperoleh dengan melakukan wawancara langsung dengan 10 responden serta melalui pengisian kuesionar yang di lakukan oleh Petani Peternak, Blantik, pedagang dan konsumen yang di gunakan sebagai sampel. Data sekunder diperoleh dari laporan kegiatan umum dari masing-masing pedagang.

\section{HASIL DAN PEMBAHASAN}

Menurut Kohls dan Uhl, (2002), saluran tataniaga dibagi menjadi dua sistem penyaluran suatu produk dari produsen ke konsumen yaitu:

a. Petani peternak menjual produknya ke konsumen tanpa lembaga perantara

b. Petani peternak menjual produknya ke konsumen melalui lembaga perantara

Sedangkan berdasarkan hasil dari pengamatan pola umum aliran barang dan jasa dari produsen sampai konsumen akhir yang terjadi dalam pemasaran kambing di Kabupten Blitar,

Tabel 3. Rata-rata biaya pada saluran pemasaran ke I

\begin{tabular}{|c|c|}
\hline Uraian biaya & Rp/ekor \\
\hline -Peternak & \\
harga jual1 ekor kambing & 2.000 .000 \\
-konsumen & \\
harga beli 1 ekor kambing & 2.000 .000 \\
-Farmer's share & $100 \%$ \\
\hline
\end{tabular}

Sumber: Data Primer Diolah (2015)

Saluran pemasaran ternak kambing yang pertama (Tabel 3) mempunyai nilai farmer's share tertinggi yaitu $100 \%$, sehingga saluran tersebut pemasarannya paling efisien dibandingkan dengan saluran 2, dan 3, karena biaya yang dikeluarkan paling sedikit. Hal ini sesuai pendapat Soekartawi, (2002), bahwa untuk mengukur efisiensi pemasaran adalah persentase antara biaya pemasaran dengan nilai produk yang dipasarkan dan pemasaran tidak akan efisien jika biaya pemasaran semakin besar dari nilai produk yang dipasarkan atau pemasaran yang efisien jika biaya pemasaran lebih rendah dari nilai produk yang dipasarkan. Pedagang yang terkait pada saluran pemasaran ke II adalah blantik. Peternak pada saluran ini tidak mengeluarkan biaya transportasi karena biaya sudah dikeluarkan oleh blantik. Harga kambing yang diterima blantik sebesar Rp. 1.750.000/ekor karena kondisi kambing tersebut masih berada di peternak (Tabel 4). Blantik mengeluarkan biaya sebesar Rp.31.000 dan keuntungan yang diperoleh blantik sebesar Rp.319.000/ekor. Margin pemasaran yang dikeluarkan sebesar Rp. 350.000/ekor. Harga jual ternak kambing ditingkat blantik sebesar Rp. 2.100.000/ekor.

Tabel 4. Rata-rata biaya pada saluran pemasaran ke II

\begin{tabular}{|l|r|}
\hline Uraian biaya & Rp/ekor/hari \\
& \\
\hline - Peternak \\
harga jual 1 ekor kambing & 1.750 .000 \\
-Blantik & 1.750 .000 \\
harga beli 1 ekor kambing & 30.000 \\
biaya pemasaran & 1.000 \\
-transport/pengangkutan & 31.000 \\
-retribusi pasar & 2.100 .000 \\
Jumlah biaya & 350.000 \\
Harga Jual & 319.000 \\
Margin Pemasaran & 31.000 \\
Keuntungan & \\
Total Biaya Pemasaran & \\
\hline
\end{tabular}




\begin{tabular}{|l|r|}
\hline Total Margin Pemasaran & 350.000 \\
Total Keuntungan & 319.000 \\
Farmer's Share & $83.33 \%$ \\
\hline \multicolumn{2}{|c|}{ Sumber: Data Primer Diolah (2015) }
\end{tabular}

Pedagang pada saluran pemasaran III yang terlibat antara lain blantik, pedagang besar dan konsumen. Saluran pemasaran ini blantik mengeluarkan biaya transportasi dan retribusi pasar. Biaya paling tinggi adalah biaya transportasi, yaitu sebesar Rp. 30.000/ekor. Hal ini disebabkan karena blantik harus melakukan pengangkutan ternak kambing dari peternak sampai ke pasar hewan. Blantik menjual ternak kambing dengan harga Rp. 2.100.000/ekor kepada pedagang pengepul dan keuntungan yang diperoleh blantik sebesar Rp. 319.000/ekor. Harga jual pedagang pengepul ke konsumen adalah Rp. 2.500.000/ekor sehingga margin pemasarannya sebesar Rp. 400.000/ekor.

Tabel 5. Rata-rata biaya pada saluran pemasaran ke III

\begin{tabular}{|l|r|}
\hline Uraian biaya & Rp/ekor/hari \\
\hline - Peternak & 1.750 .000 \\
Harga jual 1 ekor kambing & \\
- Blantik & 1.750 .000 \\
Harga beli 1 ekor kambing & 30.000 \\
Biaya pemasaran & 1.000 \\
-Transport & 31.000 \\
-Retribusi pasar & 2.100 .000 \\
Jumlah biaya & 350.000 \\
Harga Jual & 319.000 \\
Margin Pemasaran & \\
Keuntungan & 2.100 .000 \\
-Pedagang besar & 30.000 \\
Harga beli 1 ekor kambing & 1.000 \\
Biaya pemasaran & 25.000 \\
-Pengangkutan & 25.000 \\
-Retribusi pasar & 81.000 \\
-Pakan & 2.500 .000 \\
-Tenaga kerja & 400.000 \\
Jumla biaya & 319.000 \\
Harga jual & 112.000 \\
Marjin pemasaran & 750.000 \\
Keuntungan & 638.000 \\
Total Biaya Pemasaran & $70 \%$ \\
Total Margin Pemasaran & \\
Total Keuntungan & \\
Farmer's Share & \\
\hline Sumber Data Primer Diolah & \\
\hline
\end{tabular}

Sumber: Data Primer Diolah (2015)

Berdasarkan Tabel 3, Tabel 4, dan Tabel 5, keuntungan yang terbesar diperoleh pada saluran pemasaran pertama yaitu petani peternak sebesar $100 \%$. Sedangkan saluran pemasaran kambing di Kabupten Blitar yang paling menguntungkan bagi petani peternak adalah saluran pemasaran pertama karena saluran pemasaran tersebut petani peternak tidak mengeluarkan biaya sekecil apapun.

\section{Farmer's Share}


Farmer's share digunakan untuk membandingkan antara harga di tingkat petani peternak dengan harga di tingkat konsumen akhir. Analisis Farmer's Share memiliki hubungan negatif dengan marjin tataniaga. Semakin tinggi bagian yang diterima oleh petani peternak maka akan semakin rendah marjin tataniaga yang di peroleh pedagang dan konsumen akhir. Sedangkan menurut Kohls dan Uhl, (2002), Farmer's Share adalah perbedaan antara eceran dan marjin tataniaga dan merupakan alat analisis yang digunakan untuk mengukur efisiensi tataniaga yang dilihat dari sisi pendapatan petani.

Tabel 6. Farmer's Share

\begin{tabular}{|l|c|c|c|}
\hline $\begin{array}{c}\text { Saluran } \\
\text { Tataniaga }\end{array}$ & $\begin{array}{c}\text { Harga di tingkat petani } \\
\text { peternak (Rp/ekor) }\end{array}$ & $\begin{array}{c}\text { Harga di Tingkat } \\
\text { konsumen (Rp/ekor) }\end{array}$ & $\begin{array}{c}\text { Farmer's } \\
\text { Share } \\
(\%)\end{array}$ \\
\hline 1 & 2.000 .000 & 2.000 .000 & $100 \%$ \\
\hline 2 & 1.750 .000 & 2.100 .000 & $83.33 \%$ \\
\hline 3 & 1.750 .000 & 2.500 .000 & $70 \%$ \\
\hline
\end{tabular}

Sumber: Data Primer Diolah (2015)

Farmer's Share terbesar terdapat pada saluran pemasaran pertama yaitu petani peternak sebesar $100 \%$. Oleh karena itu petani peternak di saluran pemasaran pertama merupakan saluran pemasaran yang paling menguntungkan. Hal ini disebabkan karena pada saluran pemasaran pertama petani peternak memperoleh bagian yang paling tinggi dan tidak mengeluarkan biaya. Untuk saluran pemasaran kedua, Farmer's Share yang diperoleh blantik sebesar $83.33 \%$. Sehingga saluran pemasaran kedua merupakan saluran pemasaran yang kurang menguntungkan di bandingkan dengan saluran pemasaran kambing yang pertama. Hal ini di sebabkan pada saluran kedua blantik mengeluarkan biaya diantaranya: biaya transport dan biaya retribusi pasar. Bagi saluran ketiga yaitu pedagang besar, Farmer's Share yang diperoleh sebesar 70\%, karena pedagang besar mengeluarkan biaya seperti biaya transport, biaya parkir, biaya pakan dan tenaga kerja. Sebagai penerima harga akhir yaitu konsumen, konsumen disini mendapatkan harga yang cukup tinggi sebagai penerima harga akhir.

\section{Rasio Keuntungan dan Biaya}

Penyebaran keuntungan pada setiap lembaga tataniaga diukur melalui analisa rasio keuntungan dan biaya. Hal ini sesuai dengan pernyataan Sugiarto, (2005), tentang tingkat efisiensi tataniaga dapat juga diukur melalui besarnya rasio keuntungan terhadap biaya tataniaga. Dengan demikian semakin meratanya penyebaran rasio keuntungan dan biaya, maka dari segi operasional sistem tataniaga semakin efisien.

Besarnya rasio keuntungan dan biaya pada setiap saluran pemasaran dapat dilihat Tabel 7, Tabel 8, dan Tabel 9.

Tabel 7: Rasio pada saluran pemasaran ke 1

\begin{tabular}{|l|c|}
\hline \multicolumn{1}{|c|}{ Pelaku Pasar } & Saluran tataniaga 1 (Rp/ekor) \\
\hline Petani peternak & 2.000 .000 \\
$\Pi i$ & 0 \\
$\mathrm{Ci}$ & $100 \%$ \\
$\mathrm{Rasio} \Pi \mathrm{i} / \mathrm{Ci}$ & \\
\hline
\end{tabular}

Sumber: Data Primer Diolah (2015)

Pada saluran pemasaran pertama, ditingkat petani peternak, rasio keuntungan dan biaya adalah 0. Karena pada saluran pertama di tingkat petani peternak tidak mengeluarkan biaya pemasaran sama sekali. Berdasarkan Tabel 4, untuk saluran pemasaran kedua, rasio keuntungan dan biaya terbesar terdapat pada blantik yaitu sebesar 10,29. Rasio ini 
menunjukkan bahwa setiap Rp.100 per ekor biaya yang dikeluarkan akan menghasilkan keuntungan sebesar Rp.1029 per ekor.

Tabel 8: Rasio pada saluran pemasaran ke 2

\begin{tabular}{|l|c|}
\hline \multicolumn{1}{|c|}{ Pelaku Pasar } & Saluran Tataniaga 2 (Rp /ekor) \\
\hline Petani peternak & \\
$\Pi i$ & 1.750 .000 \\
$\mathrm{Ci}$ & 0 \\
Rasio $\Pi i / \mathrm{Ci}$ & 0 \\
\hline Blantik & \\
$\Pi i$ & 319.000 \\
$\mathrm{Ci}$ & 31.000 \\
Rasio $\Pi i / \mathrm{Ci}$ & 10,29 \\
\hline
\end{tabular}

Sumber: Data Primer Diolah (2015)

Pada saluran ketiga, rasio keuntungan dan biaya yang terbesar terdapat pada pedagang besar yaitu sebesar 3,7. Rasio ini menunjukkan bahwa setiap Rp. 100 per ekor biaya tataniaga yang dikeluarkan maka akan menghasilkan keuntungan Rp. 370 per ekor. Sedangkan rasio keuntungan dan biaya di tingkat petani peternak sebesar 0 .

Tabel 9: Rasio pada saluran pemasaran ke 3

\begin{tabular}{|l|l|}
\hline \multicolumn{1}{|c|}{ Pelaku Pasar } & \multicolumn{1}{|c|}{ Saluran Tataniaga 3 (Rp /ekor) } \\
\hline Petani peternak & \\
$\Pi i$ & 1.750 .000 \\
$\mathrm{Ci}$ & 0 \\
$\mathrm{Rasio} \Pi \mathrm{i} / \mathrm{Ci}$ & 0 \\
\hline Pedagang besar & \\
$\Pi i$ & 299.000 \\
$\mathrm{Ci}$ & 81.000 \\
$\mathrm{Rasio} \Pi \mathrm{i} / \mathrm{Ci}$ & 3,7 \\
\hline
\end{tabular}

Sumber: Data Primer Diolah (2015)

\section{Kesimpulan}

- Marjin tataniaga kambing di Pasar Hewan Wlingi dikelompokkan menjadi tiga saluran, marjin paling besar pada saluran ke 3 sebesar Rp 750.000,- pada saluran ini terjadi proses jual beli dari peternak > lembaga perantara (blantik + pedagang pengepul) $>$ konsumen.

- Farmers share pada saluran 1 sebesar $100 \%$, pada saluran 2 sebesar $83.33 \%$, pada saluran 3 sebesar 70\%. Ini menunjukkan bahwa saluran 1 lebih menguntungkan di banding saluransaluran lainnya karena tidak adanya biaya yang dikeluarkan untuk proses penjualan.

\section{DAFTAR PUSTAKA}

Badan Pusat Statistik. 2014. statistik indonesia. BPS. Jakarta. 2014. Jawa timur dalam angka. BPS jawa timur.

Budiarto, Arif. 2006. Tatalaksana dan Produkstivitas Kambing Peranakan Etawah pada Peternakan Rakyat Kecamatan Kaligesing, Kabupaten Purworejo. Skripsi. Program Studi Teknologi Produksi Ternak, Fakultas Peternakan, Institut Pertanian Bogor. 
Daniel M. 2004. Pengantar Ekonomi Pertanian. Jakarta: Bumi Aksara

Disnak. Jatimprov. Go. Id. 2014.

Indhra, Rya Paramitha. 2007. Analisis Daya Saing dan Efisiensi Tataniaga Nanas di Kabupaten Blitar, Jawa Timur. Skripsi. Program Studi Ekonomi Pertanian dan Sumberdaya, Fakultas Pertanian, Institut Pertanian Bogor.

Fitria, Noer Astri. 2004. Sistem Pemasaran Pisang di Kabupaten Cianjur. Skripsi. Fakultas Pertanian. Institut Pertanian Bogor.

Kohls, Richard L. and Joseph N. Uhl. 2002. Marketing of Agricultural Products. prentice hall. new jersey

Marimin, N Maghfiroh. 2010. Aplikasi Teknik Pengambilan Keputusan dalam Manajemen Rantai Pasok. Bogor: IPB Press.

Nachrowi DN, H Usman. 2006. Ekonometrika: Untuk Analisis Ekonomi dan Keuangan. Jakarta: Lembaga Penerbit Fakultas Ekonomi Universitas Indonesia.

Nuryono, Rahmat. 2012. Studi Kelayakan Pengembangan Pasar Hewan di Kabupaten Bekasi.

Permadi, Galih. 2008. Analisis Tataniaga Kambing Peranakan Ettawa (PE) di Kabupaten Purworejo, Jawa Tengah. Skripsi. Program Studi Ekonomi Pertanian danSumberdaya, Fakultas Pertanian, Institut Pertanian Bogor.

Soekartawi. 2002. Prinsip Dasar Manajemen Pemasaran Hasil-hasil Pertanian. Raja Grafindo Persada, Jakarta.

Sudiono, A. 2002. Pemasaran Pertanian. UMM Press. Malang.

Suriyana, Nanang. 2005. Analisis Tataniaga Beras di Pasar Tradisional dan Modern di DKI Jakarta. Skripsi. di DKI Jakarta. Skripsi. Departemen Iimu-Ilmu Sosial Ekonomi Pertanian, Fakultas Pertanian, Institut Pertanian Bogor.

Sugiarto at al. 2005. Ekonomi Mikro. Cetakan ke-3 Jakarta; PT Gramedia Pustaka Utama. $514 \mathrm{hlm}$.

Tambunan TTH. 2003. Perkembangan Sektor Pertanian di Indonesia: Beberapa Isu Penting. Jakarta: Ghalia Indonesia.

Yulianto P, C Saparinto. 2010. Pembesaran Sapi Potong Secara Intensif. Jakarta: Penebar Swadaya. 